\title{
Prevention of Infectious Diseases due to Immunosuppression and Vaccinations in Asian Patients with Inflammatory Bowel Disease
}

\author{
Shintaro Sagami Taku Kobayashi Toshifumi Hibi \\ Center for Advanced IBD Research and Treatment, Kitasato University Kitasato Institute Hospital, Tokyo, Japan
}

\section{Keywords}

Immunization coverage - Immunocompromise •

Inflammatory bowel disease $\cdot$ Live vaccine $\cdot$ Vaccination

\begin{abstract}
Background: Inflammatory bowel disease (IBD) patients with immunocompromise have a high risk of developing complications related to viral infections. Western countries were the first to formulate vaccine guideline. Asian countries developed their national and international vaccine guidelines a little later in order to reduce the risk of mortality from viral infections. However, no studies to date have examined the differences in vaccinations that prevail among Asian countries. Summary: This review summarizes the vaccination status and schedules in various Asian countries for immunocompromised IBD patients. Vaccination rates, regardless of the specific vaccine, were high in Japan, South Korea, and China and low in India and the Philippines. Vaccine schedules differed by country, and outbreaks of measles and rubella were seen due to low vaccination rates in Southeast
\end{abstract}

\section{KARGER}

(c) 2018 S. Karger AG, Basel

E-Mail karger@karger.com

www.karger.com/iid
Asia and South Asia. Live vaccines cannot be administered during immunosuppressive treatment. Infection with measles, mumps, and varicella during immunosuppressive therapy carries a high risk of mortality, and thus confirmation of immunization status is recommended as soon as IBD is diagnosed and, when possible, live vaccines should be administered before the initiation of immunosuppressive treatment. In patients seronegative for hepatitis $B$, administration of the hepatitis B vaccine is also recommended. Key Messages: Physicians, while considering severity of outbreaks, should understand the differences in vaccination status that exist among the various Asian countries and regions.

(c) 2018 S. Karger AG, Basel

\section{Introduction}

Inflammatory bowel disease (IBD) causes chronic inflammation in the gastrointestinal tract, which is often difficult to treat, as the etiology is unknown. However, the pathology is thought to be related to an exaggerated im- 
mune response. In the past 20 years, treatment for IBD has advanced greatly, and many new therapeutic agents have been developed. Many of these therapies suppress the immune response, and the resultant increase in incidence and severity of infections associated with the use of these medications is a matter of concern. One approach to address these concerns is appropriate immunization for vaccine-preventable diseases (VPD). Vaccines may be inactivated or live, and live vaccines are contraindicated during immunosuppressive therapy. Once immunosuppressive treatment is initiated, live vaccines can no longer be given, and treatment must be halted in some cases to allow vaccination.

Japan experienced a measles outbreak in 2007, and 2018 and a rubella outbreak in 2013, mostly among college students, raising societal concerns. Vaccine schedules, immunization rates, and the endemic status of infections vary by country and region, and so understanding the current situation in each country and region is important. IBD patients have a higher risk of VPD compared with the general population; therefore, childhood vaccine records and seropositivity status must be determined in each patient as soon as possible after IBD is diagnosed [1].

In this article, we evaluate measured titers of rubella, measles, varicella, and mumps viruses in IBD patients in Japan compared with previously reported values and discuss the differences in vaccine guidelines and coverage in various Asian countries and the management of IBD patients.

\section{Immunization Coverage in Japan}

\section{Live Vaccines}

Of the VPD, vaccines for tuberculosis, rubella, measles, varicella, and mumps are live vaccines, and the timing of vaccination is important in relation to immunosuppressive therapy for IBD. Past medical history of infections and immunization history should be obtained at the first visit, and if the patient does not have a history of infection or vaccination, 2 doses of a live vaccine should be administered [2, 3]. However, according to a study in Japan, about $40 \%$ of patients did not remember whether they had previously contracted measles, mumps, rubella (MMR), or varicella, and a third of patients are unsure of their vaccination status, highlighting the insufficiency of history alone and the importance of measuring titer levels [4]. In a study on the seropositivity rate of rubella, measles, varicella, and mumps in Japan, Naganuma et al. [4] reported in 2013 that the seronegativity rate of IBD patients (defined as anti-rubella Immunoglobulin $\mathrm{G}(\mathrm{IgG})<10 \mathrm{IU} / \mathrm{mL}$, antimeasles IgG $<16 \mathrm{IU} / \mathrm{mL}$, anti-mumps/varicella zoster IgG $<4 \mathrm{IU} / \mathrm{mL}$ ) for measles, mumps, rubella, and varicella were $34,37,30$, and $5 \%$ respectively. There are various methods for measuring titers, including the neutralization method, enzyme immunoassay (EIA), hemagglutination inhibition, enzyme-linked fluorescent immunoassay, latex turbidimetric immunoassay, and chemiluminescent EIA, depending on the target antibody. For the IBD patients at our institution, we measured specific antibody levels for MMR, and varicella using EIA, which has a high sensitivity and high versatility. Measles titers were measured in 246 patients ( 168 ulcerative colitis [UC] cases, 74 Crohn's disease [CD] cases, 4 Bechet's disease [BD] cases), mumps titers in 193 patients (136 UC cases, $54 \mathrm{CD}$ cases, 3 BD cases), rubella titers in 247 patients ( $168 \mathrm{UC}$ cases, $75 \mathrm{CD}$ cases, $4 \mathrm{BD}$ cases), and varicella in 254 patients (173 UC cases, $76 \mathrm{CD}$ cases, $5 \mathrm{BD}$ cases).

In the present study, seronegativity rates for measles, mumps, rubella, and varicella were $32.5,37.1,32.0$, and $5.1 \%$, respectively, similar to the rates reported by $\mathrm{Na}$ ganuma et al. $[5,6]$. In addition, in a study on healthcare workers in major hospitals in Japan, in which seronegativity was defined as $\operatorname{IgG}<4 \mathrm{IU} / \mathrm{mL}$ by the EIA method, the reported seronegativity rates were $7.4 \%$ for measles, $16.1 \%$ for mumps, $8.4 \%$ for rubella, and $0.8 \%$ for varicella $[4,7-11]$, and when we computed the seronegativity rates of our IBD patients using the same cutoff value, the rate was $3.0 \%$ for measles, $37.1 \%$ for mumps, $14.1 \%$ for rubella, and $5.1 \%$ for varicella, indicating higher seronegativity rates for healthcare workers in the general population were for IBD patients, with the exception of measles. Although the difference in assay methods prohibits an accurate comparison, seronegativity rates in Asian countries and 2 European countries are shown in Table 1. In Japan, universities and professional schools are increasingly conducting vaccination programs, and so healthcare workers in Japan likely had a lower seronegativity rate compared with those in our study. If possible, immunization history should be obtained at the time of the IBD diagnosis, and in cases without a history of infection and with inadequate vaccination, the titers for MMR, and varicella should be measured and all patients should be vaccinated [12]. However, for now, not all vaccines are covered by health insurance in Japan; thus, vaccination in all cases is practically difficult and infeasible. Never- 
Table 1. Seronegative rates of antibodies against MMR and varicella

\begin{tabular}{|c|c|c|c|c|c|c|c|c|}
\hline \multirow[t]{2}{*}{ Population } & \multicolumn{2}{|l|}{ Japan } & \multirow{2}{*}{$\begin{array}{l}\text { South Korea } \\
\text { general }\end{array}$} & \multirow{2}{*}{$\begin{array}{l}\text { China } \\
\text { general }\end{array}$} & \multirow{2}{*}{$\begin{array}{l}\text { Philippines } \\
\text { general }\end{array}$} & \multirow{2}{*}{$\begin{array}{l}\text { India } \\
\text { general }\end{array}$} & \multirow{2}{*}{$\begin{array}{l}\text { Spain } \\
\text { general }\end{array}$} & \multirow{2}{*}{$\begin{array}{l}\text { Germany } \\
\text { general }\end{array}$} \\
\hline & general & $\begin{array}{l}\text { IBD } \\
\text { (our group) }\end{array}$ & & & & & & \\
\hline Measles & 7.4 & 3.0 & 18.5 & - & - & 9.5 & 6.3 & 8.5 \\
\hline Mumps & 16.1 & 37.1 & - & - & - & 32.0 & 9.2 & 19.7 \\
\hline \multirow[t]{2}{*}{ Rubella } & 8.4 & 14.1 & - & $9.8^{*}$ & 15.4 & 16.6 & 2.5 & 9.9 \\
\hline & & & & 32.4 & & & & \\
\hline Varicella & 5.1 & 5.1 & - & - & - & 25.8 & 1.8 & 3.1 \\
\hline
\end{tabular}

theless, knowledge of the different vaccination rates by region and age is beneficial for the diagnosis of infectious diseases.

\section{Measles}

Although $88 \%$ of countries throughout the world by 2005 had a vaccine program that included 2 doses of the measles vaccine, Japan did not begin 2-dose administration of the vaccine until 2006. The antibody titers of vaccinated individuals increase through repeated contact with the virus, which is known as booster effect, but given the decrease in outbreaks of measles and rubella, antibody levels may decrease after a single administration. Indeed, in 2008, a total of 11,013 cases of measles were reported in Japan, and patient age was mostly in their teens to 30s [13]. Our study on IBD patients showed a $30 \%$ seronegativity rate in those aged $10-40$ years who had received only 1 dose, but the study did not include patients less than 10 years of age or those who have received 2 doses; it should be noted that their antibody level may decrease further. An increase in measles infection rate and mortality rate in IBD patients has not been reported anywhere in the world. However, a study in France found that none of the 36 measles patients who were admitted to the intensive care unit were vaccinated, and all 3 of those patients (8.3\%) who had been undergoing immunosuppressive therapy after renal transplant died after developing acute respiratory distress syndrome [14]. In addition, the mortality rate from measles in immunocompromised patients was high at $20-83.3 \%$. The cause of death was either pneumonia or encephalitis as a complication of measles [15-17]. Also, measles re-infection has been reported in a rheumatoid arthritis patient receiving an anti-tumor necrosis factor (TNF)- $\alpha$ agent in Japan $[15,18]$, and the relationship between immunosuppressive treatments/anti-TNF- $\alpha$ agents and severe measles should be examined. It remains unclear whether live vaccines should be administered during treatment with anti-integrin antibodies such as vedolizumab and other biologics. A case has been reported of the MMR vaccine administered during vedolizumab therapy in a patient with ileocolonic $\mathrm{CD}$, in whom antibodies were detected 8 weeks after vaccination and no side effects were seen at the 3-month follow up [19], but further examination of vaccination during biologic treatment other than antiTNF- $\alpha$ antibodies is necessary.

\section{Mumps}

In developed countries, individuals are vaccinated against rubella, measles, and mumps in early childhood, before the onset of IBD. Thus, the risk of these infections is considered low [20]. In Japan however, although the MMR vaccine was introduced in 1989, the incidence of aseptic meningitis caused by the mumps vaccine was unexpectedly high, so MMR vaccination was stopped in 1993. In 2006, the routine administration of measles and rubella vaccine was introduced, but not the administration of mumps vaccine; as such, many individuals are seronegative for mumps [21]. In IBD patients in Japan aged 10-60 years, the seronegativity rate was around $40 \%$ (Fig. 1). In other Asian countries aside from South Korea, mumps vaccination is not routinely administered, and the seronegativity rate is suspected to be higher than in Western countries. In terms of the prog- 


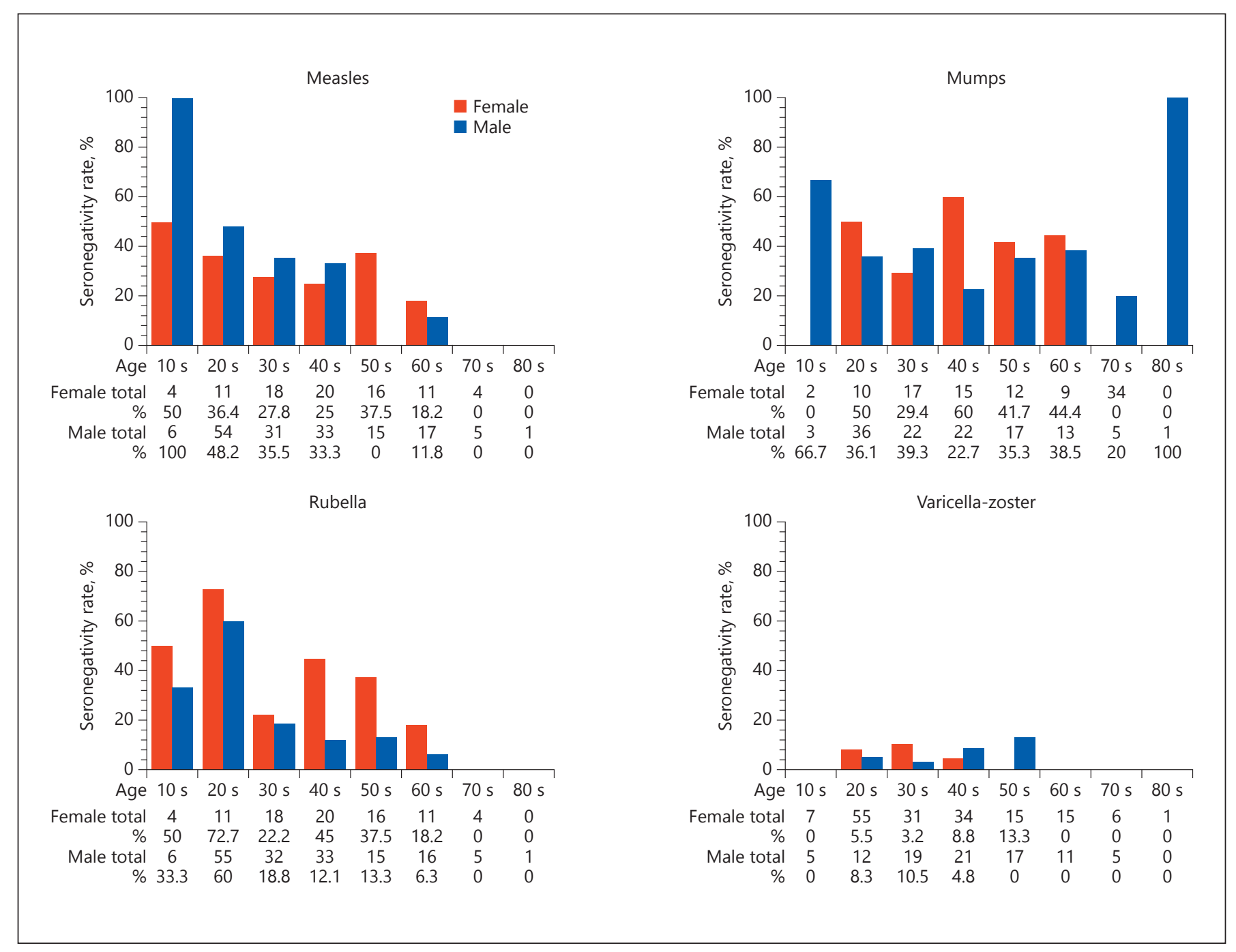

Fig. 1. The seronegativity rates against measles, mumps, rubella, and varicella-zoster viruses in Japanese patients.

nosis of patients who contract mumps during immunosuppressive therapy, there have been no case reports and its effect on disease severity remains unclear. However, it should be noted that cases of fatal mumps meningitis after hematopoietic stem cell transplantation for severe immunodeficiency have been reported in the United States and the United Kingdom [22].

\section{Rubella}

In Japan, vaccination against rubella became mandatory for 12-year-old girls in 1977, and in 1994 changed to 12-90-month-old boys and girls and 12-15-year-old unvaccinated boys and girls (until 2003). This was yet again changed from mandatory to recommended, and consequently many children were not vaccinated. Indeed, in Japanese IBD patients, women aged 40 years and above who did not receive routine vaccination, and men and women in their 20s who were born before 2003 had high seronegativity rates (Fig. 1). Under these conditions, in 2013, there was a mumps outbreak of 14,359 cases, and since many of the cases were women in their 20 s, congenital rubella syndrome was noted in as many as 45 patients $[23,24]$. Moreover, even in the vaccinated generation, if only a single dose were given without a booster effect, the individual may later become seronegative. With the high seronegativity rate among women of reproductive age, vaccination should be recommended, given the risk of congenital rubella syndrome. No 
reports of rubella infection in IBD patients or patients undergoing immunosuppressive treatment have been made. Thus, the prognosis in patients receiving immunosuppressive therapy or immunodeficient patients is unclear. A case has been reported in Australia of live mumps vaccine administration in an immunocompromised patient who had been receiving methotrexate and 6-mercaptopurine for acute lymphoid leukemia treatment for 3 months and who developed acute arthritis and arthralgia 1 month after vaccination, with seroconversion of anti-mumps Immunoglobulin $M$ [25]. Administration of the mumps vaccine should be avoided during immunosuppressive therapy, as with other live vaccines.

\section{Varicella}

In Japan, the varicella vaccine became part of the routine vaccine schedule in October 2014, and the number of patients in the vaccinated age group has since decreased. Of 20 IBD patients who contracted varicella while immunocompromised, $25 \%$ (5/20 cases) were reported to have died [26]. IBD patients who are immunocompromised due to treatment often cannot receive the varicella live vaccine. Improving herd immunity to prevent the spread of varicella zoster virus is effective to protect these patients from the threat of varicella zoster virus. In a study conducted at our institution, there was a wide age range among seronegative individuals, from age 20-50 years (Fig. 1), and of the 13 seronegative patients, 5 had received immunosuppressive treatment (adalimumab 3 cases, tacrolimus 1 case, thiopurine 1 case), highlighting the importance of improving herd immunity [27]. A case has been reported in the United States of a CD patient who contracted varicella after initiating infliximab therapy, developed fulminant hepatitis and disseminated intravascular coagulation, and eventually died [28]. Notably, another study reported a $20 \%$ mortality rate among patients who developed disseminated varicella while immunocompromised [29]. As for herpes zoster, an increase in incidence in IBD patients treated with steroids, immunomodulating agents, or anti-TNF- $\alpha$ agents has been reported, with a hazard ratio of 3.7 (95\% CI 1.8-7.5) for patients treated with 2 or more agents [30]. An increase in herpes zoster risk is also known with Janus kinase inhibitor use, and its risk has been reported to be particularly high in East Asia [31, 32]. However, there have also been reports of safe vac-

Vaccination in Asian IBD Patients cination during anti-TNF- $\alpha$ agent use [33], and inactivated vaccines are also under development. Thus, immunization during immunosuppressive therapy may become possible in the future.

\section{Bacille Calmette-Guérin}

The prevalence of tuberculosis in Japan was 17 per 100,000 population as of 2015 , which was lower than that in other Asian countries, such as 322 in the Philippines, 217 in India, 80 in South Korea, and 67 in China, yet was still higher than the low-prevalence standard of 10 , as is the case in many developed countries [34]. Therefore, in many Asian countries including Japan, Bacille CalmetteGuérin (BCG) is generally administered during infancy. BCG is preventive against severe miliary and pulmonary tuberculosis [35], but its efficacy in preventing tuberculosis in immunocompromised patients is unclear. Since the live pathogen remains in the body for several months after vaccination [36], immunization of IBD patients who may undergo immunosuppressive therapy is not recommended. In the United Kingdom, an infant born to a mother with severe $\mathrm{CD}$ who continued infliximab therapy during pregnancy developed disseminated mycobacterial infection after receiving BCG at 3 months of age and died. Thus, care must be taken in deciding when to administer BCG in a patient with a mother receiving antiTNF- $\alpha$ antibodies [37]. In addition, BCG may lead to a false positive tuberculin skin test, so the interferon- $\gamma$ release assay (IGRA; QuantiFERON-TB Gold In-Tube and T-SPOT.TB) is widely used for diagnosis of latent tuberculosis in countries and regions where BCG is administered [38]. However, IGRA may become negative when performed during steroid or immunosuppressive therapy, so results must be evaluated cautiously [39]. Particularly in Asia, where tuberculosis is endemic and the risk of new infection is higher than that in Western countries, if an IBD patient undergoing immunosuppressive treatment such as anti-TNF- $\alpha$ antibody develops respiratory symptoms, even in the absence of history or radiographic findings of tuberculosis and with a negative tuberculin skin test or IGRA, tuberculosis must be excluded [40].

\section{Inactivated Vaccines}

Inactivated vaccines can be administered, regardless of immunosuppressive treatment [2]. Hepatitis B virus (HBV), the prevalence of which differs between Japan 
and Western countries will be discussed in detail below. However, the prevalence of influenza virus, Streptococcus pneumoniae, rotavirus, Neisseria meningitidis, tetanus, diphtheria, pertussis, human papillomavirus, and hepatitis A in Japan is similar to that in Europe and the United States. We therefore do not address these infections in this article.

\section{Hepatitis B Virus}

According to the World Health Organization (WHO), 257 million people are infected with HBV worldwide, about 900,000 people die of HBV-related diseases annually (including cirrhosis and hepatocellular carcinoma), and high-prevalence countries where the HBV carrier rate in the population is $6 \%$ or higher are concentrated in the Pan Pacific region including Asia, and Africa [41, 42]. Although the HBV prevalence in Japan is relatively low at $1 \%$, the rates in China, Vietnam, and Mongolia are very high at $5-11 \%$. Thus, it is extremely important to distinguish this situation from that prevailing in Western countries [43]. With the goal of controlling HBV infection worldwide, the WHO released a recommendation in 1991 for worldwide universal vaccination against $\mathrm{HBV}$ for all children. As a result, 184 countries introduced HBV vaccination for young children by 2014 [44]. In Taiwan, in the 10 years after universal vaccination was introduced, the hepatitis $B$ surface antigen positivity rate in 6-year-old children decreased from 10.5 to $1.7 \%$ [45]. In China also, where universal vaccination was introduced early, after 14 years of universal vaccination, the hepatitis B surface antigen positivity rate successfully decreased from 19.86 to $4.91 \%$ [46]. As of 2007, among developed countries, only 7 European countries (Denmark, Finland, Iceland, the Netherlands, Norway, Sweden, and the United Kingdom) and Japan did not follow the WHO recommendations but implemented selective vaccination, in which only children born to HBV carriers are immunized [47]. The hepatitis B surface antibody positivity rate in specimens obtained from the lifestyle-related disease health checkup for 10-year-olds conducted from 2013 to 2015 was $1.0-1.5 \%$. Japan started routine HBV vaccination in 2016, which included universal vaccination in addition to selective vaccination [48]. However, because the HBV serum antibody seronegativity rate is high at $75-80 \%$ [49], in contrast to European countries and the United States, HBV vaccination of all IBD patients is generally desirable.

\section{Regional Differences within Asia}

\section{East Asia}

As discussed above, this region characteristically has a high HBV infection rate [50]. China and South Korea have a higher vaccination rate than Japan (Table 2), and the number of HBV-infected individuals decreased dramatically after the introduction of universal $\mathrm{HBV}$ vaccination [43]. Vaccination against Haemophilus influenzae type $\mathrm{B}$ (Hib) is optional in China, and the immunization rate is unknown, but the current $\mathrm{Hib}$ immunization rate is greater than $95 \%$ in Japan and South Korea (Table 2). The Hib vaccine became available in Japan on December 19, 2008 and was initially elective. Routine vaccination was initiated on April 1, 2013.

\section{Southeast Asia}

Japanese encephalitis is among the highly prevalent diseases in this region. The Japanese encephalitis vaccine was introduced early in Japan, Taiwan, South Korea, and Thailand, and therefore, the disease has been controlled in these countries. However, in some countries such as the Philippines, the vaccine has not been introduced despite some of these countries being endemic areas (Tables 2,3) [51]. Severe cases of Japanese encephalitis in immunocompromised patients have not been reported, but vaccination prior to travel to an endemic area is recommended in guidelines $[52,53]$, and administration of the vaccine should therefore be considered in endemic countries such as the Philippines. For measles also, infants in the Philippines have been receiving 1 dose of the measles-containing vaccine $(\mathrm{MCV})$ as part of their routine vaccination program, but since 2010, 2 doses of the MMR vaccine are included in their routine vaccination program. However, as of 2013, the immunization rate of the initial MCV dose was $87.0 \%$, and that of the second MMR was very low at $54 \%$. Consequently, measles has not been eliminated (Table 2). From 2011 to 2014, supplementary immunization activities of the MCV have been conducted, yet the virus continues to spread in this region.

\section{South Asia}

The immunization program in India is still in the development phase, and the vaccination rate of the routine vaccines - BCG, diphtheria-tetanus-pertussis, oral poliomyelitis, hepatitis $B$, and measles vaccines - is at $81 \%$ and the immunization rates of elective vaccines are even 
Table 2. Percentage of target population vaccinated by antigen in various Asian countries

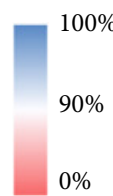

\begin{tabular}{|c|c|c|c|c|c|c|c|c|c|c|}
\hline Vaccine & Country name & 2016 & 2014 & 2012 & 2010 & 2008 & 2006 & 2004 & 2002 & 2000 \\
\hline \multirow{5}{*}{ BCG vaccine } & Japan & 98 & 93 & 95 & 99 & 90 & & & 96 & 96 \\
\hline & South Korea & 97 & 99 & 99 & 96 & 96 & 98 & 93 & 89 & 73 \\
\hline & China & 99 & 99 & 99 & 99 & 97 & 92 & 99 & 98 & 85 \\
\hline & Philippines & 76 & 79 & 89 & 83 & 93 & 91 & 91 & 85 & 81 \\
\hline & India & 89 & & 90 & 89 & 86 & 86 & 80 & 75 & 74 \\
\hline \multirow{5}{*}{ 1st DTP vaccine } & Japan & 99 & 99 & 99 & 99 & 99 & 99 & 99 & 99 & 99 \\
\hline & South Korea & 98 & 99 & 99 & 96 & 95 & 98 & 95 & 97 & 97 \\
\hline & China & 99 & 99 & 99 & 99 & 99 & 94 & 99 & 98 & \\
\hline & Philippines & 87 & 78 & 91 & 81 & 94 & 90 & 92 & 84 & 81 \\
\hline & India & 91 & & 89 & 86 & 81 & 81 & 77 & 75 & 74 \\
\hline \multirow{5}{*}{ Hepatitis B vaccine } & Japan & & & & & & & & & \\
\hline & South Korea & 93 & 92 & & 95 & 94 & 98 & 96 & 92 & 93 \\
\hline & China & 96 & 94 & 96 & 92 & 91 & 88 & 76 & & \\
\hline & Philippines & 59 & 51 & 39 & 37 & 21 & & & & \\
\hline & India & 47 & & 30 & & 3 & & & & \\
\hline \multirow{5}{*}{$\begin{array}{c}\text { Haemophilus } \\
\text { influenzae type B } \\
\text { vaccine }\end{array}$} & Japan & 99 & & & & & & & & \\
\hline & South Korea & 98 & 97 & & & & & & & \\
\hline & China & & & & & & & & & \\
\hline & Philippines & 91 & 96 & 88 & 1 & & & & & \\
\hline & India & 80 & & & & & & & & \\
\hline \multirow{5}{*}{$\begin{array}{c}\text { Oral polio virus } \\
(\mathrm{OPV}) \text { vaccine or } \\
\text { inactivated PV (IPV) } \\
\text { vaccine }\end{array}$} & Japan & 99 & 99 & 99 & 98 & 95 & 95 & 97 & 99 & 99 \\
\hline & South Korea & 98 & 99 & 99 & 95 & 92 & 98 & 90 & 99 & 99 \\
\hline & China & 99 & 99 & 99 & 99 & 99 & 94 & 99 & 98 & 90 \\
\hline & Philippines & 72 & 77 & 88 & 78 & 91 & 88 & 85 & 77 & 75 \\
\hline & India & 86 & & 79 & 76 & 69 & 66 & 58 & 58 & 57 \\
\hline \multirow{5}{*}{$\begin{array}{c}\text { Japanese encephalitis } \\
\text { vaccine }\end{array}$} & Japan & 99 & 99 & 99 & 22 & 4 & & & & \\
\hline & South Korea & 97 & 99 & 99 & 89 & 84 & 88 & & & \\
\hline & China & 99 & 99 & 99 & 99 & & & & & \\
\hline & Philippines & & & & & & & & & \\
\hline & India & 59 & & 65 & 37 & & & & & \\
\hline \multirow{5}{*}{ 1st measles vaccine } & Japan & 96 & 98 & 96 & 94 & 97 & 97 & 99 & 99 & 96 \\
\hline & South Korea & 98 & 99 & 99 & 98 & 92 & 99 & 99 & 97 & 95 \\
\hline & China & 99 & 99 & 99 & 99 & & 93 & 98 & 98 & 98 \\
\hline & Philippines & 80 & 79 & 87 & 80 & 92 & 92 & 92 & 82 & 80 \\
\hline & India & 88 & & 83 & 82 & 72 & 69 & 64 & 56 & 56 \\
\hline \multirow{4}{*}{$\begin{array}{l}\text { Pneumococcal } \\
\text { conjugate vaccine }\end{array}$} & Japan & 99 & & & & & & & & \\
\hline & South Korea & 99 & & & & & & & & \\
\hline & Philippines & 64 & 42 & & & & & & & \\
\hline & & & & & & & & & & \\
\hline
\end{tabular}

lower. In terms of infection susceptibility, no studies have compared seroprevalence between countries. However, in a cross-sectional study of 790 students in India, the serological susceptibility of measles, mumps, rubella, and varicella was $9.5,32.0,16.6$, and $25.8 \%$ respectively
(Table 1) [54]. When considering the addition of immunosuppressive therapy, some cases require consideration of administration of live vaccines, as is the case in Japan. 
Table 3. Vaccine schedule in various Asian countries

\begin{tabular}{|c|c|c|c|c|c|}
\hline & Japan & South Korea & China & Philippines & India \\
\hline BCG vaccine & 1 years & Birth-1 months & Birth & Birth & Birth \\
\hline DTP vaccine & $2,3,4$ months, 1 years $^{2}$ & $\begin{array}{l}2,4,6,15-18 \text { months, } \\
4-6 \text { years } \\
11-12 \text { years }^{2}\end{array}$ & $\begin{array}{l}3,4 \\
5 \text { months }^{2}\end{array}$ & $6,10,14$ weeks $^{3}$ & $\begin{array}{l}6,10,14 \text { weeks, } \\
16-24 \text { months, } 5 \\
\text { years }^{3}\end{array}$ \\
\hline Oral polio vaccine (or IPV) & $\begin{array}{l}3,4.5,6,18 \text { months } \\
\text { (inactivated) }\end{array}$ & $\begin{array}{l}2,4,6 \text { months } \\
4-6 \text { years } \\
\text { (inactivated) }\end{array}$ & $\begin{array}{l}3,4 \text { months, } \\
4 \text { years }\end{array}$ & $6,10,14$ weeks & $\begin{array}{l}\text { Birth } 6,10,14 \text { weeks } \\
16-24 \text { months }\end{array}$ \\
\hline Measles vaccine & - & - & - & 9 months & $9-12,16-24$ months \\
\hline $\begin{array}{l}\text { Measles mumps and rubella } \\
\text { vaccine }\end{array}$ & 1,5 years $^{5}$ & $\begin{array}{l}12-15 \text { months, } \\
4-6 \text { years }\end{array}$ & 8 months $^{5}$ & $6,10,12$ months & $\begin{array}{l}9 \text { months - } \\
2 \text { years }\end{array}$ \\
\hline $\begin{array}{l}\text { Pneumococcal conjugate } \\
\text { vaccine }\end{array}$ & $\begin{array}{l}2,3,4 \text { months, } \\
1 \text { years }\end{array}$ & $2,4,6,12-15$ months & - & $6,10,14$ weeks $^{4}$ & Up to 1 years ${ }^{4}$ \\
\hline $\begin{array}{l}\text { Pneumococcal } \\
\text { polysaccharide vaccine }\end{array}$ & $\geq 65$ years & $\geq 65$ years & - & $\geq 60$ years & - \\
\hline Varicella vaccine & 12,18 months & $12-15$ months & - & $\begin{array}{l}12-15 \text { months, } \\
4-6 \text { years }\end{array}$ & - \\
\hline
\end{tabular}

${ }^{1}$ Only tetanus toxoid; ${ }^{2}$ diphtheria and tetanus toxoid with acellular pertussis vaccine (DTaP); ${ }^{3}$ diphtheria and tetanus toxoid with whole cell pertussis vaccine $(\mathrm{DTwP}) ;{ }^{4}$ Not entire country; ${ }^{5}$ Measles and rubella vaccine.

BCG, Bacille Calmette-Guerin; DTP, diphtheria and tetanus toxoid with pertussis; IPV, inactivated polio vaccine.

\section{Conclusions}

Individuals seronegative for VPD were found in various Asian countries, and early vaccination is desirable as soon as IBD is diagnosed for patients with diseases that have a high risk of becoming severe during immunosuppressive therapy.

Given the differences among the various Asian countries and regions in vaccination schedules based on age and sex, as well as in vaccination rates, seronegativity rates, and severity of outbreaks, and given the high prevalence of tuberculosis and HBV compared with European countries and the United States, immunization guidelines for IBD patients should be established that reflect the situation in each country.

\section{Ethics Statement}

This study was approved by the Research Ethics Committee of the Kitasato Institute Hospital.

\section{Disclosure Statement}

T.K. and T.H. received lecture fees from AbbVie Inc., Kyorin Pharmaceutical Co., Ltd., Eisai Co., Ltd., Mitsubishi Tanabe Pharma Co., Ltd., EA Pharma Co., Ltd., JIMRO Co., Ltd., and ZERIA Pharmaceutical Co., Ltd. T.K. received lecture fees from Janssen, Ajinomoto Pharma, Astellas, Mochida Pharmaceutical, Asahi Kasei Medical, Takeda Pharmaceutical, Gilead Sciences, Celltrion, Nippon Kayaku, Alfresa Pharma. T.K. received consulting fees from Janssen, Pfizer, Kyorin Pharmaceutical, Mochida Pharmaceutical, Takeda Pharmaceutical, Eli Lilly, Ferring Pharmaceuticals, Nippon Kayaku, Thermo Scientific, Covidien, Alfresa Pharma. (No funding was received for this work from any of these organizations.). 


\section{References}

1 Gisbert JP, Chaparro M: Vaccination strategies in patients with IBD. Nat Rev Gastroenterol Hepatol 2013;10:277-285.

2 Reich J, Wasan S, Farraye FA: Vaccinating patients with inflammatory bowel disease. Gastroenterol Hepatol 2016;12:540-546.

3 Desalermos AP, Farraye FA, Wasan SK: Vaccinating the inflammatory bowel disease patient. Expert Rev Gastroenterol Hepatol 2015; 9:91-102.

4 Naganuma M, Nagahori M, Fujii T, Morio J, Saito E, Watanabe M: Poor recall of prior exposure to varicella zoster, rubella, measles, or mumps in patients with IBD. Inflamm Bowel Dis 2013;19:418-422.

5 Okabe N, Arakawa S, Iwata S, Okabe, Ihara T, Shiraishi T, Taya K, Fujimoto T, Mikamo H, Yasuoka A: Vaccine guidelines for medical personnel. Jpn J Infect Prev Control 2014; 29(suppl 3):S1-S14.

6 Byrne L, Brant L, Reynolds C, Ramsay M: Seroprevalence of low rubella IgG antibody levels among antenatal women in England tested by NHS blood and transplant: 2004-2009. Is rubella susceptibility increasing? Vaccine 2012;30:161-167.

7 Kang HJ, Han YW, Kim SJ, Kim YJ, Kim AR, Kim JA, Jung HD, Eom HE, Park O, Kim SS: An increasing, potentially measles-susceptible population over time after vaccination in Korea. Vaccine 2017;35:4126-4132.

8 Lao TT, Sahota DS, Law LW, Leung TY: Rubella seronegativity in antenatal screening - is it influenced by the introduction of universal childhood rubella immunization? Vaccine 2015;33:4776-4781.

9 Mou J, Griffiths SM, Fong HF, Hu Q, Xie X, $\mathrm{He} \mathrm{Y}$, Ma H, Cheng J: Seroprevalence of rubella in female migrant factory workers in Shenzhen, China. Vaccine 2010;28:78447851.

10 Lopez AL, Raguindin PF, Silvestre MA, Fabay XC, Vinarao AB, Manalastas R: Rubella and congenital rubella syndrome in the Philippines: a systematic review. Int J Pediatr 2016; 2016:8158712.

11 Arunkumar G, Vandana KE, Sathiakumar N: Prevalence of measles, mumps, rubella, and varicella susceptibility among health science students in a University in India. Am J Ind Med 2013;56:58-64.

12 Lu Y, Bousvaros A: Immunizations in chil dren with inflammatory bowel disease treated with immunosuppressive therapy. Gastroenterol Hepatol 2014;10:355-363.

13 Takeshige A, Yamaguchi M, Iwata S, Maezawa K, Kizu J: Determination of antibody titers and vaccination against epidemic viral infections in medical professionals. Jpn J Environ Infect 2014;29:23-31.

14 Rafat C, Klouche K, Ricard JD, Messika J, Roch A, Machado S, Sonneville R, Guisset O, Pujol W, Guérin C, Teboul JL, Mrozek N, Darmon M, Chemouni F, Schmidt M, Mercier E, Dreyfuss D, Gaudry S: Severe measles infection: The spectrum of disease in 36 critically ill adult patients. Medicine (Baltimore) 2013;92:257-272.

15 Kaplan LJ, Daum RS, Smaron M, McCarthy CA: Severe measles in immunocompromised patients. JAMA 1992;267:1237-1241.

16 Gray MM, Hann IM, Glass S, Eden OB, Jones PM, Stevens RF: Mortality and morbidity caused by measles in children with malignant disease attending four major treatment centres: a retrospective review. Br Med J (Clin Res Ed) 1987;295:19-22.

17 Kernahan J, McQuillin J, Craft AW: Measles in children who have malignant disease. $\mathrm{Br}$ Med J (Clin Res Ed) 1987;295:15-18.

18 Young MK, Nimmo GR, Cripps AW, Jones MA: Post-exposure passive immunisation for preventing measles. Cochrane Database Syst Rev 2014;4:Cd010056.

19 Wichmann A, Krugliak Cleveland N, Rubin DT: Safety and efficacy of live measles vaccine administered to a Crohn's disease patient receiving vedolizumab. Am J Gastroenterol 2016;111:577.

20 Takahashi E, Kurosaka D, Yoshida K, Yanagimachi M, Kingetsu I, Yamada A: Onset of modified measles after etanercept treatment in rheumatoid arthritis. Jpn J Clin Immunol 2010;33:37-41.

21 BernsteinCN,RawsthorneP,BlanchardJF:Population-based case-control study of measles, mumps, and rubella and inflammatory bowel disease. Inflamm BowelDis 2007;13:759-762.

22 Kimura T, Tsunekawa K, Ogiwara T, Tokue $\mathrm{Y}$, Nara, M, Inoue T, Obuchi T, Suto C, Ohshima K, Murakami M: Seroprevalence of measles- and mumps-specific immunoglobulin $\mathrm{G}$ among Japanese healthcare students increased during 2007-2012. Jpn J Infect Dis 2013;66:411-415.

23 Bakshi N, Lawson J, Hanson R, Ames C, Vinters HV: Fatal mumps meningoencephalitis in a child with severe combined immunodeficiency after bone marrow transplantation. J Child Neurol 1996;11:159-162.

24 Eyre TA, Pelosi E, McQuaid S, Richardson D, Newman J, Hill K, Veys P, Davies G, Orchard $\mathrm{KH}$ : Mumps virus encephalomyelitis in a 19year old male patient with an undefined severe combined immunodeficiency post-haematopoietic bone marrow transplantation: a rare fatal complication. J Clin Virol 2013;57: $165-168$.

25 Sugishita Y, Akiba T, Sumitomo M, Hayata N, Hasegawa M, Tsunoda T, Okazaki T, Murauchi K, Hayashi Y, Kai A, Seki N, Kayebeta A, Iwashita Y, Kurita M, Tahara N: Shedding of rubella virus among infants with congenital rubella syndrome born in Tokyo, Japan, 2013-2014. Jpn J Infect Dis 2016;69:418-423.

26 Geiger R, Fink FM, Solder B, Sailer M, Enders G: Persistent rubella infection after erroneous vaccination in an immunocompromised patient with acute lymphoblastic leukemia in remission. J Med Virol 1995;47:442-444.
27 Prelog M. Differential approaches for vaccination from childhood to old age. Gerontology. 2013;59:230-239.

28 Cullen G, Baden RP, Cheifetz AS: Varicella zoster virus infection in inflammatory bowel disease. Inflamm Bowel Dis 2012;18:23922403.

29 Leung VS, Nguyen MT, Bush TM: Disseminated primary varicella after initiation of infliximab for Crohn's disease. Am J Gastroenterol 2004;99:2503-2504.

30 Maillot C, Riachi G, Francois A, Ducrotte P, Lerebours E, Hemet J, Colin R: Digestive manifestations in an immunocompetent adult with varicella. Am J Gastroenterol 1997; 92:1361-1363.

31 Marehbian J, Arrighi HM, Hass S, Tian H, Sandborn WJ: Adverse events associated with common therapy regimens for moderate-tosevere Crohn's disease. Am J Gastroenterol 2009;104:2524-2533.

32 Gupta G, Lautenbach E, Lewis JD: Incidence and risk factors for herpes zoster among patients with inflammatory bowel disease. Clin Gastroenterol Hepatol 2006;4:1483-1490.

33 Winthrop KL, Yamanaka H, Valdez H, Mortensen E, Chew R, Krishnaswami S, Kawabata T, Riese R: Herpes zoster and tofacitinib therapy in patients with rheumatoid arthritis. Arthritis Rheumatol 2014;66:2675-2684.

34 Khan N, Shah Y, Trivedi C, Lewis JD: Safety of herpes zoster vaccination among inflammatory bowel disease patients being treated with anti-TNF medications. Aliment Pharmacol Ther 2017;46:668-672.

35 World Health Organization: Global tuberculosis report 2016. Geneva, World Health Organization, 2016.

36 Rodrigues LC, Diwan VK, Wheeler JG: Protective effect of BCG against tuberculous meningitis and miliary tuberculosis: a metaanalysis. Int J Epidemiol 1993;22:11541158.

37 Toussirot E, Wendling D. Bacillus calmetteguerin vaccination in a patient treated with infliximab. J Rheumatol 2005;32:2500-2501.

38 Cheent K, Nolan J, Shariq S, Kiho L, Pal A, Arnold J: Case report: Fatal case of disseminated BCG infection in an infant born to a mother taking infliximab for Crohn's disease. J Crohns Colitis 2010;4:603-605.

39 Tokuda H, Harigai M, Kameda H, Tomono K, Takayanagi N, Watanabe A, Tasaka S, Suda T, Tateda K, Kadota J: Consensus statements for medical practice: Biological agents and lung disease [Abridged English translation by the Japanese Respiratory Society]. Respir Investig 2017;55:229-251.

40 PapayP, Primas C, Eser A, Novacek G,Winkler S, Frantal S, Angelberger S, Mikulits A, Dejaco C, Kazemi-Shirazi L, Vogelsang H, Reinisch W: Retesting for latent tuberculosis in patients with inflammatory bowel disease treated with TNF-alpha inhibitors. Aliment Pharmacol Ther 2012;36:858-865. 
41 Jauregui-Amezaga A, Turon F, Ordas I, Gallego M, Feu F, Ricart E, Panes J: Risk of developing tuberculosis under anti-TNF treatment despite latent infection screening. J Crohns Colitis 2013;7:208-212.

42 Debeuckelaere C, De Munter P, Van Bleyenbergh P, De Wever W, Van Assche G, Rutgeerts $\mathrm{P}$, Vermeire $\mathrm{S}$ : Tuberculosis infection following anti-TNF therapy in inflammatory bowel disease, despite negative screening. J Crohns Colitis 2014;8:550-557.

43 World Health Organization: Hepatitis B, 2017. http://www.who.int/mediacentre/factsheets/fs204/en/ (accessed October 1, 2017).

44 Schweitzer A, Horn J, Mikolajczyk RT, Krause G, Ott JJ: Estimations of worldwide prevalence of chronic hepatitis B virus infection: a systematic review of data published between 1965 and 2013. Lancet 2015;386:1546-1555.

45 World Health Organization: Immunization Coverage, 2017. http://www.who.int/mediacentre/factsheets/fs378/en/ (accessed October 1, 2017).
46 Hsu HM, Lu CF, Lee SC, Lin SR, Chen DS: Seroepidemiologic survey for hepatitis $B$ virus infection in Taiwan: the effect of hepatitis B mass immunization. J Infect Dis 1999;179: 367-370.

47 Xiao J, Zhang J, Wu C, Shao X, Peng G, Peng Z, Ma W, Zhang Y, Zheng H: Impact of hepatitis $B$ vaccination among children in Guangdong Province, China. Int J Infect Dis 2012; 16:e692-e696.

48 Zuckerman J, van Hattum J, Cafferkey M, Gjørup I, Hoel T, Rummukainen ML, Weiland O: Should hepatitis B vaccination be introduced into childhood immunisation programmes in northern Europe? Lancet Infect Dis 2007;7:410-419.

49 National Institute of Infectious Diseases. Acute hepatitis B, April 2006-December 2015. IASR 2016;37:147-148. http://www.niid.go. jp/niid/en/iasr-vol33-e/865-iasr/6692-438te. html (accessed April 22, 2018).
50 Ikeda M, Yamamoto H, Kaneko M, Oshima, $\mathrm{H}$, Takahashi $\mathrm{H}$, Umemoto $\mathrm{K}$, Watanabe $\mathrm{K}$, Hashimoto Y, Ohno I, Mitsunaga S, Okusaka $\mathrm{T}$ : Screening rate for hepatitis B virus infection in patients undergoing chemotherapy in Japan. Int J Cin Oncol 2016;21:1162-1166.

51 Chang MH, You SL, Chen CJ, Liu CJ, Lee CM, Lin SM, Chu HC, Wu TC, Yang SS, Kuo HS, Chen DS: Decreased incidence of hepatocellular carcinoma in hepatitis B vaccinees: A 20year follow-up study. J Natl Cancer Inst 2009; 101:1348-1355.

52 Japanese encephalitis: Surveillance and immunization in Asia and the Western Pacific, 2016. Wkly Epidemiol Rec 2017;92:323-331.

53 Wasan SK, Baker SE, Skolnik PR, Farraye FA: A practical guide to vaccinating the inflammatory bowel disease patient. Am J Gastroenterol 2010;105:1231-1238.

54 Manthiram K, Blood EA, Kuppuswamy V, Martins Y, Narayan A, Burmeister K, Parvathy $\mathrm{K}$, Hassan A: Predictors of optional immunization uptake in an urban south Indian population. Vaccine 2014;32:3417-3423. 